\title{
Neurociencias y comunicación: el comienzo de una saludable amistad
}

\author{
Neurosciences and Communication: the Beginning of a \\ Healthy Friendship
}

\author{
Aitor Ugarte
}

\section{Cómo citar el artículo}

Ugarte, A. (2013). Neurociencias y comunicación: el comienzo de una saludable amistad. Revista de Comunicación y Salud, 3(1), pp. 1-4.

DOI: http://doi.org/10.35669/revistadecomunicacionysalud.2013.3(1).1-4

Los espíritus puros pertenecen, si acaso, a universos que el ser humano aún desconoce. Lo propio de este mundo es que las cosas se ofrezcan mestizas, simultáneas, polisémicas, paradójicas, confusas, caóticas, no lineales: complejas, en definitiva. Por eso no aciertan quienes, desde la llustración a nuestros días, defienden la fragmentación de las artes y las ciencias. Por eso también simplifican y yerran quienes sostienen que se puede alcanzar un gran saber sobre lo humano a base de especializarse en algo muy singular y concreto. Por eso da en el punto quien dijo aquello de "nada de lo humano me es ajeno" (Terencio).

Quizá se pueda alcanzar la sabiduría volcando la vida profesional en el estudio de la célula o del comportamiento del hígado ante un determinado estrés alostático, pero difícilmente se 
conseguirá solo únicamente a golpe de neuroanatomía o hepatología. Lo más probable es que también se tenga que abrir el foco a Cervantes y García Márquez, a la Declaración Universal de los Derechos Humanos o al interés por civilizaciones como la egipcia, la inca o la azteca.

La controversia no es nueva.

Allá por 1959 C.P. Snow introdujo con fuerza este debate sobre la separación entre la ciencia y las humanidades. La escisión de estas "dos culturas", como las denominó con éxito el físico y novelista británico en su ensayo, provocaban un gran problema para el avance de la educación y la resolución de los problemas del mundo, según denunció de C.P. Snow en su ensayo The Two Cultures and the Scientific Revolution.

A las preocupaciones de Snow, que no entendía un mundo sin que las personas cultas hubieran leído a Shakespeare pero tampoco sin que conocieran la segunda ley de la termodinámica, respondió en los años 90 del siglo pasado John Brockman introduciendo el concepto de la "tercera cultura". En The Third Culture: Beyond the Scientific Revolution (1995), Brockman reivindicaba el papel de los intelectuales tradicionales para aquellos científicos y pensadores que, desde el conocimiento extraído de sus trabajos empíricos, habían comenzado a trasladar al público explicaciones sobre las más fundamentales cuestiones de nuestras vidas: quiénes y qué somos, cómo funciona el universo, de qué manera opera la mente humana, qué es la conciencia...

Una de las cuestiones más significativas de esta autodenominada "tercera cultura", que constantemente se actualiza en la revista de internet Edge (www.edge.org), radica en que sus seguidores proponen una reinterpretación del significado de lo humano, más allá de modelos unidimensionales como el homo oeconomicus, rationalis, faber, ludens o videns.

En esta fascinante tarea desarrollan un papel fundamental las neurociencias.

Nacidas en el seno de la investigación biomédica, y con una relación directa con el ámbito de la salud y la enfermedad, las neurociencias se ocupan de la estructura y funcionamiento del cerebro humano. Los experimentos básicos y los diseños empíricos de investigación neurocientífica, cuyo auge trata de los años 90 del siglo XX, conviven hoy día con aplicaciones prácticas de los sucesivos hallazgos sobre cómo trabaja y cuáles son las reacciones del cerebro humano ante diferentes estímulos. Tecnologías novedosas como las resonancias magnéticas funcionales (fMRI, por sus siglas en inglés) o las tomografías por emisión de positrones (PET, también según siglas en inglés) han resultado fundamentales para desarrollar la investigación neurocientífica y ahora, con su expansión y abaratamiento, pueden dar un vuelco a la visión tradicional de las que tradicionalmente hemos llamado ciencias sociales. $Y$, entre ellas, por supuesto, la comunicación.

Intuyo que neurociencias y comunicación tan sólo han comenzado una saludable amistad que preveo fructífera en muchos aspectos y a diversos niveles. Para no hablar de lo inabarcable ni abundar en la especulación, en este artículo quiero condensar los resultados de un sugerente experimento neurocomunicativo en el campo de la salud pública, realizado por Falk, Berkman y Lieberman, y cuyos resultados se publicaron en mayo de 2012. 
Esta investigación abre nuevas vías de exploración en una de las cuestiones fundamentales para la comunicación persuasiva: ¿cómo se puede predecir mediante el estudio de grupos pequeños de población que un mensaje, una campaña publicitaria o una acción de mercadotecnia va a resultar eficaz a escala colectiva? Las respuestas equivocadas a la pregunta anterior han supuesto que cientos de millones de dólares, euros o la moneda que quieran imaginar se hayan tirado a la basura con campañas persuasivas ineficaces, cuando no contraproducentes.

Esta cuestión es, pues, absolutamente protagonista para definir el éxito o fracaso de las actividades de promoción de la salud y prevención de la enfermedad, entre otras muchas acciones comunicativas. Hasta le ha dado respuesta -en el mejor de los casos- mediante la utilización de encuestas, grupos de discusión (focus groups) en los que se valoraba lo que los integrantes decían, pre-test de campañas, y entrevistas individuales a expertos o población a la que va a dirigido el mensaje persuasivo (target).

El proyecto de Falk, Berjman y Lieberman da un paso más introduciendo las neurociencias en este proceso. Su experimento plantea como pregunta de investigación si la actividad cerebral (en este caso de una región llamada corteza prefrontal medial) de quienes participan en un focus group predice la conducta colectiva de una población mejor que las respuestas de estos mismos participantes a un cuestionario al uso. Y la conclusión es que, efectivamente, en los mismos individuos, la actividad cerebral es un mejor indicador del comportamiento futuro que sus respuestas a una serie de preguntas.

Para la investigación, realizada en el área de Los Ángeles (EE.UU.), los autores seleccionaron a 30 personas muy fumadoras (15 hombres y 15 mujeres, de diferentes etnias y nivel socioeconómico) unidas por su fuerte intención de dejar el tabaco. En formato de focus groups expusieron a esta muestra de población a 3 conjuntos de spots televisivos ( 3 campañas publicitarias, en definitiva) diseñados profesionalmente para motivar y ayudar a grandes fumadores a abandonar este hábito. Todos los spots terminaban ofreciendo una línea telefónica especializada del Instituto Nacional del Cáncer como primer "interlocutor" para quien se decidiera a dar el paso. Para medir el éxito o la eficacia de los spots a nivel poblacional se utilizó el aumento de las llamadas a ese teléfono entre el mes anterior y el mes posterior a la emisión de las 3 campañas. Con el objetivo de no incurrir en sesgos se tuvieron en cuenta diferentes variables de confusión, tanto en la medición de la actividad neuronall como en la eficacia de los 3 grupos de spots.

La conclusión de que el focus group "neural" predice el efecto mediático a escala colectiva de una manera más atinada que el focus group tradicional, en el que se trabaja sobre el discurso explícito e implícito de los intervinientes, abre vías de enorme interés teórico y práctico para el estudio de la comunicación persuasiva y de sus implicaciones en el procesamiento de la información, en las actitudes y en la conducta individual y colectiva. Superadas las viejas teorías conductistas del estímulo-respuesta, en las que se suponía un control total sobre los receptores, y en entredicho algunas de las actuales herramientas de investigación social, las nuevas vías ligadas a las neurociencias presentan opciones interesantes para ir reduciendo el margen de error en las acciones comunicativas en salud. 
Tras la lectura del artículo de Falk, Berkman y Lieberman no cabe sino plantearse, por ejemplo, el grado de validez de los métodos tradicionales de predicción de la eficacia de los mensajes mediáticos; métodos basados en "lo que dicen los individuos que sienten y que piensan" sobre los contenidos persuasivos a los que son expuestos.

El asunto no es menor. Conlleva implicaciones éticas que deberán ser estudiadas y también habrá que ajustar la relación de las neurociencias con los determinantes sociales y culturales de la salud.

En cualquier caso, y para concluir, más allá de que contribuyan o no a cambiar paradigmas, las neurociencias -tan complejas ellas, tan promiscuas, tan innovadoras y sugestivas, tan "tercera cultura"- se merecen un papel mucho mayor al que tienen actualmente dentro de la investigación en comunicación (y salud).

\section{$\overline{\text { Referencias }}$}

Brockman, John. (1995). The Third Culture: Beyond the Scientific Revolution. Nueva York: Touchstone.

Falk, Emily B.; Berkman, Elliot T. y Lieberman, Matthew D. (2012). From Neural Responses to Population Behavior: Neural Focus Group Predicts Population-Level Media Effects. Psychological Science. Vol. 23, nº 5, pp. 439-445.

Snow, Charles Percy. (1959). The Two Cultures and the Scientific Revolution. Cambridge: Cambridge University Press. 